\title{
Consumption of healthy food and ultra-processed products: comparison between pregnant and non-pregnant women, Vigitel 2018
}

Ana Maria Pita Ruiz 1

(iD https://orcid.org/0000-0002-9020-8600

Daniela de Assumpção 2

(iD https://orcid.org/0000-0003-1813-996X

Deborah Carvalho Malta 3

iD https://orcid.org/0000-0002-8214-5734

Priscila Maria Stolses Bergamo Francisco 4

iD https://orcid.org/0000-0001-7361-9961

1,2,4 Faculdade de Ciências Médicas. Universidade Estadual de Campinas. Rua Tessália Vieira de Camargo, 126. Cidade Universitária Zeferino Vaz. Campinas, SP, Brasil. CEP: 13.083-887. E-mail: ampitar13@gmail.com

${ }^{3}$ Departamento de Enfermagem Materno-Infantil e Saúde Pública. Universidade Federal de Minas Gerais. Belo Horizonte, MG, Brasil.

\begin{abstract}
Objectives: to characterize pregnant women's eating habits and compare them to women of reproductive age, and to analyze the association between pregnancy and eating habits.

Methods: a cross-sectional study with 13,108 women aged 18 to 50 years (179 pregnant women), included in the Vigitel 2018 telephone survey. Eating habits were assessed by the frequency of food consumption considered as food quality markers and by food eaten in previous day. NOVA classification was used to categorize food into: natural/minimally processed, and ultra-processed food products. The differences were verified by Pearson's Chi-square test and Poisson multiple regression.

Results: in pregnant women, we observed lower percentages of natural juice intake (27.5\%) and fruit (10.1\%) 0-2 times/week, and higher percentages of juice (36.4\%) 3-4 times and fruit $(74.2 \%) \geq 5$ times/week compared to non-pregnant women. No differences were detected in the daily frequencies of food intake among the women. The day before the interview, almost $95 \%$ of the pregnant women consumed ultra-processed products. Pregnant women reported a lower frequency of soft drink consumption (12.3\%) and sauces (7.4\%) than non-pregnant women.

Conclusion: pregnant women and non-pregnant women had high consumption of ultraprocessed products, highlighting the necessity of interventions, aiming to promote healthy eating.

Key words Prenatal nutrition, Food consumption, Industrialized food, Epidemiological surveys
\end{abstract}




\section{Introduction}

Healthy eating is a determinant of individuals' health status. The golden rule of the Food Guide for the Brazilian Population, is that, "always prefer fresh or minimally processed foods and culinary preparations to ultra-processed food", brings recommendations that seek to promote a healthy diet prioritizing the consumption of cereals, beans, roots and tubers, milk, fruit, vegetables, eggs, meat, water, and culinary preparations made with these food, as well as small amounts of salt, sugar and fat.1,2 Consumption of ultra-processed food, such as soft drinks, powdered juices, cookies, packet snacks, margarine, sweetened yogurts, instant noodles, chicken nuggets and, among others, should be avoided at all stages of life. 1,2

The high consumption of ultra-processed food, due to their high concentration of sugars, fat, salt, food dyes and other additives, 3 is associated with the development of chronic non-communicable diseases for both general population and pregnant women.3,4 A study that analyzed pregnant women's diet in Botucatu/SP/Brazil found that one quarter of the average energy consumption came from ultraprocessed food, with higher numbers in younger pregnant women, of higher schooling and having their first child, during the trimesters of pregnancy. 5 In Ribeirão Preto/SP/Brazil, ultra-processed food accounted for $32 \%$ of the total calories consumed by pregnant women, and the consumption was higher among younger women with a better socioeconomic level. ${ }^{6}$ In Campinas/SP/Brazil, a study with high-risk pregnant women showed the negative impact of ultra-processed food items on the nutritional profile, leading to higher energy density, high sugar content sodium, fat, and low protein and nutrient content. ${ }^{7}$ It is noteworthy that national investigations on the consumption of ultra-processed food during pregnancy are still scarce.

In pregnant women, unhealthy eating is a risk factor for the occurrence of anemia, 8 excessive weight gain, 9,10 hypertension 9,11 and gestational diabetes, 12 postpartum weight retention, preterm delivery, low birth weight 12 and other conditions that affect the woman and fetus' health. A prospective cohort study (2009-2014) with 660 pregnant women from Mexico City showed an association between better diet quality, evaluated by the Maternal Diet Quality Score, and lower risk of children with low birth weight (odds ratio $=0.22 ; p<0.05$ ). 13 In a population-based cohort in Sweden, pregnant women with the worst diet quality had a 4.3 times higher risk of excessive weight gain compared to the segment with the best food quality ( $p=0.010)$; in addition, weight gain increased the risk of emergency cesarean delivery by two times.

In the gestational period, physiological changes and fetal growth increase the demand for energy and nutrients, 14 highlighting the need to monitor food consumption and nutritional status. Maternal eating habits stimulate the child's tastebuds through the amniotic fluid and breast milk, emphasizing the importance of the golden rule of the Brazilian Food Guide to promote the acceptance of food from six months of life onwards. 2,15,16

Considering that healthy eating is essential for the mother and child's health, and that data on the Brazilian pregnant women's eating patterns are scarce (although interesting to the academic community, managers, and healthcare professionals), the objectives of this study were: to characterize pregnant women's eating habits and compare them to women of reproductive age, living in Brazilian capitals and in the Federal District, and analyze the association between pregnancy and eating habits.

\section{Methods}

This is a cross-sectional population-based study that used data from the Sistema de Vigilância de Fatores de Risco e Proteção para Doenças Crônicas por Inquérito Telefônico (Vigitel, 2018) (Surveillance System for Risk and Protective Factors for Chronic Diseases by Telephone Survey), including registrations of women aged between 18 and 50 years, living in households served by at least one landline phone. Our telephone survey used a probabilistic sample selected as follows: initially, a systematic and stratified drawing was carried out based on postal code (CEP) of at least 5,000 telephone lines in each city, from the electronic register of fixed residential lines of telephone companies. Then, the lines drawn in each capital and Federal District (DF) were redrawn and divided into replicas of 200 lines, each replica reproducing the same proportion of lines per postal code from the original register. In the second stage of the sampling, one of the adults ( $\geq 18$ years of age) living in the selected households was chosen, a step that was performed after the identification, among the lines drawn, of those who were not eligible for the system. Some of the lines for this non-eligibility were business, out of service, or non-existent lines, as well as phone numbers that did not respond to six calls made at different times/days. 17

The minimum sample size of approximately two thousand individuals in each city is necessary to estimate, with a $95 \%$ confidence coefficient and a 
maximum error of two percentage points, the frequency of any risk factor in the adult population. To compensate for the bias of non-universal coverage of fixed telephone lines, weighting factors were used. The final weight (post-stratification) attributed to each individual interviewed allowed for the statistical inference of the results of the system for the adult population of each city, considering that it equals the sociodemographic composition estimated for the adult population with telephone by the Vigitel sample in each city, that is, the one that estimates the total adult population in the same city in the year of the research.18 We considered the following variables in the sociodemographic composition: sex (female and male), age group (18-24, 25 $34,35-44,45-54,55-64$ and 65 and more) and schooling level (without formal education or incomplete elementary school, complete elementary or incomplete high school, incomplete higher education, and complete higher education). All information on the sample design of the Vigitel telephone survey, as well as the procedures used in the interviews, were published. 17

In this study, women between 18 and 50 years old were distributed in two subgroups - pregnant and non-pregnant - and were described according to the following sociodemographic variables: age group (18 to 29 or 30 to 50 years old), schooling ( 0 to 11 or 12 or more years of schooling), skin color/race (white, black, or mixed), marital status (without spouse or with spouse) and possession of health insurance (yes or no).

In Vigitel, eating habits were investigated through questions that assessed the weekly and daily frequency of food consumption that were considered food quality markers. Raw vegetables, cooked vegetables, fruit, natural fruit juice, soft drinks or artificial juice were the selected markers, and its consumption frequencies were categorized into 0 to 2,3 to 4 , and 5 or more days a week. The daily frequency of the intake of these food was analyzed, as well as the type of soft drink or artificial juice. Food consumption was also checked the day before, through the question: "Now I'm going to list some food and I'd like for you to tell me if you ate any of them yesterday (from the moment you woke up to when you went to sleep)" (yes or no). The food were organized into two groups based on NOVA classification, which characterizes the food according to the extent and purpose of industrial processing2:

Natural or minimally processed food covered the following food groups:

* Raw and cooked vegetables: lettuce, cabbage, broccoli, watercress, spinach, tomato, cucumber, zucchini, eggplant, squash or beet.

* Fruit: papaya, mango, melon, pequi, orange, banana, apple or pineapple.

* Meat and eggs: beef, pork, chicken, fish, fried eggs, boiled eggs or scrambled eggs.

* Legumes and oilseeds: beans, peas, lentils, chickpeas, peanuts, cashew nuts or Brazil-nuts.

* Milk.

While ultra-processed food products covered:

* Soft drinks

* Other sugary drinks: boxed juices, canned juices or juice powders.

* Sweets and desserts: flavored yogurt, chocolate drinks, cookies, snack cakes, chocolate, ice cream, gelatin, flan or other industrialized desserts.

* Packet snacks or salted crackers.

* Sauces: mayonnaise, ketchup or mustard.

* Margarine.

* Processed meat: hot dogs, sausages, bologna or ham.

* Ready-to-eat food products: instant noodles, package soups, frozen lasagna or other frozen readyto-eat dishes.

* Sliced bread, hot dog or hamburger buns.

In the statistical analyses, initially, we estimated the weighted percentage distribution of women according to the selected characteristics, and the differences between the groups were verified via Pearson's chi-square test with second order correction (Rao \& Scott), considering a significance level of $5 \%$. Then, we estimated the percentage frequencies of food consumption, according to the categories of weekly and daily food consumption frequency between pregnant and non-pregnant women, and the differences were verified by the prevalence ratios (PR) adjusted for age, marital status and possession of health insurance. The percentages of unprocessed or minimally processed and ultra-processed food consumption for the subgroups were also evaluated. The analyses were performed in the statistical program Stata 15.1, in the survey module, which considers the complex sampling of the research.

In this study, the groups of fresh or minimally processed food (total) and cereals, roots, and tubers (rice, polenta pasta, couscous, corn, potatoes, cassava, yams, squashes, carrots, sweet potatoes, or okra) were not presented in the results due to the insufficient number of observations, which made it impossible to produce estimates with adequate precision according to the condition of interest.

The objectives of this research were informed to all the participants at the time of the telephone contact and the informed consent form was replaced 
by the verbal one. The study was approved by the National Commission of Ethics in Human Beings Research, Ministry of Health, under Opinion Number 355,590 on July 26, 2013.

\section{Results}

We analyzed the data of 13,108 adult women between 18 and 50 years old, of whom $1.93 \%$ $(n=179)$ were pregnant at the time of the interview. The mean age of pregnant women was 29.7 years old $(\mathrm{CI} 95 \%=28.3-31.1)$ and, regarding to sociodemographic characteristics, most were between 18 and 29 years old (50.4\%), with schooling up to 11 years $(60.9 \%)$ and with health insurance $(61.0 \%)$. Regarding to skin color/race and marital status, $49.3 \%$ declared themselves mixed skin color and $61.6 \%$ had a partner at the time of the study (Table $1)$.

Pregnant women had a higher proportion of fruit juice consumption with a frequency of 3 to 4 days a week (36.4\% versus $19.1 \%)$ and fruit 5 or more days a week ( $74.2 \%$ versus $48.5 \%)$, in relation to nonpregnant women (Table 2).
Table 3 shows that no significant differences were detected in the daily frequencies of food consumption and the type of soft drink among pregnant women and women of reproductive age.

The comparison between pregnant and non-pregnant women regarding to the consumption of fresh or minimally processed and ultra-processed food on the day before the interview is shown in Table 4. The percentage of consumption of ultra-processed items was similar between groups, reaching $94.8 \%$ in pregnant women and $90.4 \%$ in non-pregnant women. Only soft drinks $(12.3 \%$ versus $25.1 \%$ ) and sauces (7.4\% versus $16.6 \%$ ) did pregnant women present lower percentages of consumption.

\section{Discussion}

This study compares the pregnant women and women of reproductive age (18 to 50 years old) eating habits, living in Brazilian capitals and the Federal District, who participated in the Vigitel telephone survey (2018). The results indicate that both pregnant women and non-pregnant women had a high consumption of ultra-processed products.

Table 1

Sociodemographic characteristics of pregnant and non-pregnant women living in Brazilian capitals and the Federal District. Vigitel, Brazil, 2018.

\begin{tabular}{|c|c|c|c|c|c|}
\hline \multirow[t]{2}{*}{ Variables } & \multicolumn{2}{|c|}{ Pregnant woman } & \multicolumn{2}{|c|}{ non-pregnant woman } & \multirow[t]{2}{*}{$p^{a}$} \\
\hline & $\mathrm{n}$ & $\%$ & $\mathrm{n}$ & $\%$ & \\
\hline Age group (years) & & & & & 0.0122 \\
\hline $18-29$ & 71 & 50.41 & 3,523 & 33.51 & \\
\hline $30-50$ & 108 & 49.59 & 9,406 & 66.49 & \\
\hline Schooling (years of studying) & & & & & 0.8935 \\
\hline $0-11$ & 76 & 60.94 & 6,283 & 60.06 & \\
\hline 12 or more & 103 & 39.06 & 6,646 & 39.94 & \\
\hline Race/skin color & & & & & 0.8362 \\
\hline White & 69 & 39.30 & 5,046 & 43.04 & \\
\hline Black & 23 & 11.42 & 1,174 & 11.51 & \\
\hline Mixed & 83 & 49.28 & 6,148 & 45.45 & \\
\hline Marital status & & & & & 0.0077 \\
\hline No spouse & 56 & 38.44 & 6,970 & 57.65 & \\
\hline With spouse & 123 & 61.56 & 5,907 & 42.35 & \\
\hline Health insurance & & & & & 0.0406 \\
\hline No & 72 & 39.04 & 6,090 & 53.45 & \\
\hline Yes & 107 & 60.96 & 6,805 & 46.55 & \\
\hline
\end{tabular}

$\mathrm{n}=$ Number of women in the unweighted sample; \%= Weighted percentage to adjust the sociodemographic distribution of the Vigitel sample to the distribution of the adult population of each city projected in 2018; ap-value of the Pearson's Chi-square test (Rao-Scott). 
Table 2

Weekly frequency and adjusted prevalence ratios of food consumption in pregnant and non-pregnant women living in Brazilian capitals and the Federal District. Vigitel, Brazil, 2018.

\begin{tabular}{|c|c|c|c|c|c|}
\hline Food (weekly frequency) & $\begin{array}{l}\text { Pregnant } \\
\text { women } \%\end{array}$ & $\begin{array}{c}\text { Non-pregnant } \\
\text { women } \%\end{array}$ & $p^{a}$ & PR adjustedb & $p^{c}$ \\
\hline \multicolumn{6}{|c|}{0 to 2 days a week } \\
\hline Raw vegetables & 29.20 & 28.92 & 0.9671 & 1.11 & 0.7200 \\
\hline Cooked vegetables & 29.53 & 39.49 & 0.1289 & 0.64 & 0.1280 \\
\hline Natural fruit juice & 27.55 & 51.63 & 0.0002 & 0.40 & 0.0010 \\
\hline Fruit & 10.10 & 27.85 & 0.0003 & 0.29 & 0.0010 \\
\hline Soft drinks or artificial juices & 82.95 & 74.99 & 0.1305 & 1.77 & 0.0690 \\
\hline \multicolumn{6}{|c|}{3 to 4 days a week } \\
\hline Raw vegetables & 26.90 & 29.02 & 0.7659 & 0.85 & 0.6290 \\
\hline Cooked vegetables & 33.57 & 31.31 & 0.7470 & 1.10 & 0.7610 \\
\hline Natural fruit juice & 36.40 & 19.15 & 0.0052 & 2.36 & 0.0060 \\
\hline Fruit & 15.68 & 23.66 & 0.1217 & 0.60 & 0.1170 \\
\hline Soft drinks or artificial juices & 5.92 & 10.97 & 0.1387 & 0.46 & 0.0890 \\
\hline \multicolumn{6}{|c|}{$\geq 5$ days a week } \\
\hline Raw vegetables & 43.89 & 42.05 & 0.7954 & 1.05 & 0.8720 \\
\hline Cooked vegetables & 36.90 & 29.21 & 0.2591 & 1.42 & 0.2630 \\
\hline Natural fruit juice & 36.05 & 29.22 & 0.2631 & 1.21 & 0.4830 \\
\hline Fruit & 74.22 & 48.48 & $<0.0001$ & 3.11 & $<0.0001$ \\
\hline Soft drinks or artificial juices & 11.13 & 14.04 & 0.4958 & 0.74 & 0.4220 \\
\hline
\end{tabular}

ap-value of the Pearson's Chi-square test (Rao-Scott); b Prevalence ratio (PR) adjusted for age, marital status, and health insurance; $c p$-value of the Wald test.

Table 3

Daily frequency and adjusted prevalence ratios of food consumption in pregnant women and non-pregnant women living in Brazilian capitals and the Federal District. Vigitel, Brazil, 2018.

\begin{tabular}{|c|c|c|c|c|c|}
\hline Food (daily frequency) & $\begin{array}{l}\text { Pregnant } \\
\text { women } \%\end{array}$ & $\begin{array}{c}\text { Non-pregnant } \\
\text { women } \%\end{array}$ & $p^{a}$ & PR adjustedb & $p^{c}$ \\
\hline \multicolumn{6}{|l|}{ Natural or minimally processed } \\
\hline \multicolumn{6}{|l|}{ Raw vegetables } \\
\hline 1 time (lunch or dinner)d & 62.17 & 71.93 & 0.1787 & 1.50 & 0.1970 \\
\hline 2 times (lunch and dinner) & 37.83 & 28.07 & & & \\
\hline \multicolumn{6}{|l|}{ Cooked vegetables } \\
\hline 1 time (lunch or dinner)d & 55.12 & 65.83 & 0.1471 & 1.42 & 0.2450 \\
\hline 2 times (lunch and dinner) & 44.88 & 34.17 & & & \\
\hline \multicolumn{6}{|l|}{ Natural fruit juice } \\
\hline 1 to 2 cupsd & 81.74 & 80.57 & 0.8145 & 0.91 & 0.7760 \\
\hline$\geq 3$ cups & 18.26 & 19.43 & & & \\
\hline \multicolumn{6}{|l|}{ Fruit } \\
\hline 1 to 2 timesd & 76.11 & 83.34 & 0.2199 & 1.49 & 0.2710 \\
\hline$\geq 3$ times & 23.89 & 16.66 & & & \\
\hline \multicolumn{6}{|l|}{ Ultra-processed food } \\
\hline \multicolumn{6}{|l|}{ Soft drinks or artificial juices } \\
\hline 1 to 2 cups/cansd & 90.60 & 80.64 & 0.0621 & 0.47 & 0.0920 \\
\hline$\geq 3$ cups/cans & 9.40 & 19.36 & & & \\
\hline \multicolumn{6}{|l|}{ Type of soft drink } \\
\hline Regulard & 88.35 & 85.75 & 0.8050 & & \\
\hline Diet/light/zero & 7.18 & 7.77 & & 0.86 & 0.8510 \\
\hline Both & 4.47 & 6.48 & & 0.66 & 0.3970 \\
\hline
\end{tabular}

aValue of the Pearson's Chi-square test (Rao-Scott); b Prevalence ratio (PR) adjusted for age, marital status, and health plan; $c p$-value of the Wald test; $d$ Reference category used for comparison. 
Table 4

\begin{tabular}{|c|c|c|c|c|c|}
\hline Food group & $\begin{array}{l}\text { Pregnant } \\
\text { women } \%\end{array}$ & $\begin{array}{c}\text { Non-pregnant } \\
\text { women } \%\end{array}$ & $p^{a}$ & PR adjustedb & $p^{c}$ \\
\hline \multicolumn{6}{|l|}{ Natural or minimally processed* } \\
\hline Raw and cooked vegetables & 79.71 & 79.54 & 0.9789 & 0.93 & 0.8690 \\
\hline Fruit & 86.40 & 77.08 & 0.0894 & 1.90 & 0.0920 \\
\hline Meat and eggs & 96.74 & 94.45 & 0.4418 & 1.65 & 0.4860 \\
\hline Legumes and oilseeds & 78.21 & 74.65 & 0.5024 & 1.17 & 0.5940 \\
\hline Milk & 58.72 & 55.14 & 0.6311 & 1.15 & 0.6330 \\
\hline Ultra-processed food** & 94.79 & 90.39 & 0.0700 & 1.81 & 0.1150 \\
\hline Soft drinks & 12.34 & 25.14 & 0.0098 & 0.39 & 0.0060 \\
\hline Other sugary drinks & 25.24 & 24.83 & 0.9486 & 0.96 & 0.9050 \\
\hline Sweets and desserts & 60.79 & 57.72 & 0.6838 & 1.03 & 0.9340 \\
\hline Packet snacks & 21.88 & 22.48 & 0.9100 & 0.99 & 0.9880 \\
\hline Sauces & 7.43 & 16.57 & 0.0015 & 0.38 & 0.0010 \\
\hline Margarine & 54.06 & 46.11 & 0.2529 & 1.40 & 0.2080 \\
\hline Ready-to-eat food products & 11.47 & 5.80 & 0.1890 & 2.23 & 0.1630 \\
\hline Processed meat & 17.80 & 24.26 & 0.2283 & 0.62 & 0.1300 \\
\hline Sliced bread, hot dog or hamburger buns & 43.36 & 33.74 & 0.0643 & 1.57 & 0.1040 \\
\hline
\end{tabular}

aPearson Chi-square test $p$-value (Rao-Scott); b Prevalence ratio (PR) adjusted for age, marital status, and health insurance; $c p$-value of the Wald test. *Estimates were not presented due to insufficient number of observations; ${ }^{* *}$ Consumption of at least one ultra-processed food.

Pregnant women had a more frequent consumption of fruit and natural juices, and less frequent of soft drinks and industrialized sauces. On the other hand, they did not differentiate regarding the consumption of essential food in the gestational period such as vegetables, legumes and oilseeds, meat and eggs and milk, and those considered unnecessary such as soft drinks, sweets, snacks and margarine.

Regarding to sociodemographic characteristics, pregnant women were similar to those observed in other studies. In a national hospital-based study (2011-2012) with data on 23,894 puerperal women was observed that $70.4 \%$ were between 20 and 34 years old and $10.5 \%$ were 35 years or older; most of them declared themselves mixed skin color $(56.1 \%)$, reported having a partner $(81.4 \%)$ and almost $9 \%$ had completed higher education. ${ }^{19}$ According to the National Health Survey (2013), among women that reported having had prenatal care in their late pregnancy, the subgroups aged 20 to 29 years old (50.6\%), 30 to 39 years old $(36.2 \%)$, mixed skin color $(49.9 \%)$ and with complete higher education (16.8\%) comprised most of the sample.20 These comparisons denote the representativeness of the Vigitel sample, whose results are similar to those of national hospital and population-based studies deve- loped with pregnant women.

The findings of this study showed higher frequencies of fruit and natural juice intake in pregnant women. A study that compared pregnant women's eating habits assisted at a primary care in the city of Botucatu/SP of women of reproductive age in Brazilian capitals (2010), found no differences in the percentages of regular consumption of fruit and vegetables, pregnant women presented a percentages of $30.2 \%$ (18 to 24 years old), $36.8 \%$ ( 25 to 34 years old) and $37.5 \%$ (35 to 44 years old). ${ }^{21}$ In Spain, a study that monitored pregnant women until the postpartum period observed that the recommendation of fruit consumption (3 to 4 portions/day) was not met, with an average of 1.7 per portions/day; furthermore, when comparing the mean intake in the three trimesters and postpartum, there was a reduction of $221.4 \mathrm{~g} /$ day to $189.0 \mathrm{~g}$ /day $(p<0.001) .22$

Fruit are indispensable in food and are recommended to prevent various chronic diseases, given by their content of dietary fibers and other nutrients, as well as bioactive compounds with antioxidant action. 18 Estimates of a systematic review on food consumption patterns in 195 countries indicate that insufficient fruit intake $(<250 \mathrm{~g} /$ day $)$ has caused 2 
million deaths and 65 million years of disability adjusted life-years (DALYs) in the world, in 2017.23 A systematic review study with meta-analysis found that a $200 \mathrm{~g} /$ day increase in fruit intake would reduce the relative risk of stroke $(18 \%)$, cardiovascular disease $(13 \%)$, coronary artery disease $(10 \%)$, cancer $(4 \%)$ and all-cause of mortality (15\%). ${ }^{24}$ Data from three prospective cohorts conducted in the United States showed an association between fruit consumption and lower risk of diabetes, especially blueberries, grapes/raisins, apples/pears and bananas. 25 The dark peel of the fruit such as blueberry, jabuticaba, blackberry, and grapes is rich in anthocyanins; while white and red grapes have high levels of resveratrol, apples and prunes or plums contain quercetin and chlorogenic acid, which are antioxidant compounds that contribute to prevent disease. 25

A study that analyzed data from prospective cohorts found that the consumption of natural juice ( $\geq 1$ portion/day) increases the risk of diabetes by $21 \%$, and that the equivalent replacement of juice by whole fruit significantly reduces the risk of a disease. 25 Compared to the whole fruit, natural juice has lower dietary fiber content, higher glycemic load and does not provide the same feeling of satiety, therefore, preference should be given to the consumption of whole fruit. 2,26 The preparation of juice results in the loss of nutrients that are sensitive to light, oxygen and heat, making it advisable to reduce the time of interval for ingestion, besides avoiding the use of sieves and the addition of sugars. 2,26 For pregnant women, it is recommended to ingest citrus fruit at lunch and dinner to increase the absorption of non-heme iron present in food of plant origin. 27

In this study, it is noteworthy that approximately $95 \%$ of the pregnant women reported the consumption of ultra-processed products on the previous day and that soft drinks and sauces (mayonnaise, ketchup, or mustard) were the only food products in which pregnant women had a lower frequency of consumption. In the city of Botucatu/SP, regular soft drink consumption ( $\geq 5$ days/week) was $17.5 \%$ (18 to 24 years old), $18.9 \%$ ( 25 to 34 years old) and $8.3 \%$ (35 to 44 years old) among pregnant women, which were lower percentages than those observed among non-pregnant women: $36.5 \%, 31.0 \%$ and $26.0 \%$, respectively. 20

The consumption of ultra-processed food products impairs the nutritional quality of the diet, increasing the content of added sugar, sodium, fat, and reducing the content of dietary fiber, potassium, and protein.2,28 In the United Kingdom, a cross- sectional study identified a high prevalence of inadequacy for added sugar (77.2\%), saturated fat $(80.2 \%)$, dietary fiber $(93.6 \%)$, sodium $(86.7 \%)$, and protein $(92.3 \%)$ in the sample segment with higher intake of ultra-processed products. ${ }^{3}$ Pregnant women ought to remove these food products from their daily diet, due to the risk of excessive weight gain and other negative health outcomes for both women and children.10,12 A study conducted with pregnant women in Ribeirão Preto/SP detected a significant association between the consumption of ultraprocessed products and a higher inflammatory potential in the diet.29

In this study, the pregnant women's eating habits were similar to the non-pregnant women, except for the consumption of fruit and juices, which was more frequent, and soft drinks and sauces, which was less frequent. Regular consumption of vegetables was reported by less than half of the pregnant women, and no differences were found in the daily consumption of vegetables, fruit, juices, milk and beans/oilseeds. In general, these findings agree with other studies, such as that of Gomes et al.,21 which identified high prevalence of eating practices considered healthy and unhealthy among pregnant women. An integrative review that sought to investigate the Brazilian pregnant women's eating habits revealed that, in most of the analyzed studies, the results differed from the national recommendations on food. 30 These findings reinforce the necessity to disseminate the recommendations of the current Food Guide for the general population, and to develop campaigns and educational materials to support health professionals to adapt the guidelines of the Guide into the gestational period.

As for the limitations of this study, memory bias may interfere with the participants' ability to report the frequencies of food intake. The number of pregnant women in this sample was small, and may not represent the general universe; however, in comparison between the groups regarding sociodemographic characteristics, the analysis showed differences for age (younger), marital status (with spouse) and possession of health insurance. The representativeness of the Vigitel sample was restricted to individuals who had a fixed residential telephone line and who lived in the capitals of the 26 Brazilian States and in the Federal District in 2018. To minimize this limitation, weighting factors were applied that reduce the differences observed in populations with and without telephone lines, and the weigh on the post-stratification allowed the estimates to be extrapolated to all individuals. 17 In our study, the estimates were based on the weights calcu- 
lated by the Vigitel survey and the age cut was defined by the condition of interest (pregnant - yes or no).

This study identified that pregnant women and women of reproductive age had high consumption of ultra-processed products. In comparison between the groups, pregnant women presented more positive results regarding the consumption of fruit and natural juices, with higher percentages, and soft drinks and sauces, with lower percentages. The results highlight the necessity of interventions aimed to promote pregnant women and women in general to eating healthy, in addition to the importance of adapting official dietary guidelines for pregnant women.

\section{Acknowledgments}

The authors of this article would like to thank the technical teams at the Health Surveillance Secretary

\section{References}

1. Brasil. Ministério da Saúde. Secretaria de Atenção à Saúde. Departamento de Atenção Básica. Guia Alimentar para a População Brasileira. 2 Ed. Brasília, DF; 2014.

2. Monteiro CA, Cannon G, Moubarac J-C, Levy RB, Louzada MLC, Constante PJ. The UN Decade of Nutrition, the NOVA food classification and the trouble with ultraprocessing. Public Health Nutr. 2017; 21 (1): 5-17.

3. Rauber F, Louzada MLC, Steele EM, Millett C, Monteiro CA, Levy RB. Ultra-Processed Food Consumption and Chronic Non-Communicable Diseases-Related Dietary Nutrient Profile in the UK (2008-2014).Nutrients. 2018; 10 (5): 587.

4. Monteiro CA, Cannon G, Lawrence M, Louzada MLC, Machado PP. Ultra-processed foods, diet quality, and health using the NOVA classification system. Roma: Food and Agriculture Organization of the United Nations, 2019. [citado 4 jun 2020]. Disponível em: http://www.fao.org/3/ca5644en/ca5644en.pdf

5. Gomes CB, Malta MB, Benício MHD, Carvalhaes MABL. Consumption of ultra-processed foods in the third gestational trimester and increased weight gain: a Brazilian cohort study. Public Health Nutr. 2020; 1-9.

6. Sartorelli DS, Crivellenti LC, Zuccolotto DCC, Franco LJ. Relationship between minimally and ultra-processed food intake during pregnancy with obesity and gestational diabetes mellitus. Cad Saúde Pública. 2019; 35 (4): e00049318.

7. Paulino DSM, Pinho-Pompeu M, Assumpção D, Kasawara KT, Surita FG. Dietary intake profile in high-risk pregnant women according to the degree of food processing.J Matern Fetal Neonatal Med. 2020; 13; 1-7. of the Ministry of Health, involved in the implementation and operation of the VIGITEL system and the Coordination of the Higher Education Personnel Improvement (CAPES) for financing the doctoral scholarship of Ana Maria Pita Ruiz.

\section{Authors' contribution}

Ruiz AMP: data analysis, literature review, writing and submission of the article. Assumpção D: conception of the study, review of data analysis and literature, writing of the article and revision of the final version. Malta DC: critical review of data analysis and the final version of the manuscript. Bergamo Francisco PMS: conception of the study, review of data analysis, writing of the text and critical revision of the final version.

8. Di Renzo GC, Spano F, Giardina I, Brillo E, Clerici G, Roura LC. Iron deficiency anemia in pregnancy. Womens Health. 2015; 11 (6): 891-900.

9. Waksmańska W, Bobiński R, Ulman-Włodarz I, Pielesz A. The differences in the consumption of proteins, fats and carbohydrates in the diet of pregnant women diagnosed with arterial hypertension or arterial hypertension and hypothyroidism. BMC Pregnancy Childbirth. 2020; 20 (1): 29.

10. Augustin H, Winkvist A, Bärebring L. Poor Dietary Quality is Associated with Low Adherence to Gestational Weight Gain Recommendations among Women in Sweden. Nutrients. 2020; 12 (2): 317.

11. Masho SW, Urban P, Cha S, Ramus R. Body Mass Index, Weight Gain, and Hypertensive Disorders in Pregnancy. Am J Hypertens 2016; 29(6):763-71. https://doi.org/10.1093/ajh/hpv184.

12. Goldstein RF, Abell SK, Ranasinha S, Misso ML, Boyle JA, Harrison CL, et al. Gestational weight gain across continents and ethnicity: systematic review and metaanalysis of maternal and infant outcomes in more than one million women. BMC Med. 2018; 16: 153.

13. Ancira-Moreno M, Vadillo-Ortega F, Rivera-Dommarco JA, Sánchez BN, Pasteris J, Batis C, et al. Gestational weight gain trajectories over pregnancy and their association with maternal diet quality: Results from the PRINCESA cohort. Nutrition. 2019; 65: 158-66.

14. Mousa A, Naqash A, Lim S. Macronutrient and micronutrient intake during pregnancy: An overview of recent evidence. Nutrients. 2019; 11:443. 
15. Paglia L.Taste development and prenatal prevention.Eur J Paediatr Dent. 2019; 20 (4): 257

16. Brasil. Ministério da Saúde. Secretaria de Atenção Primária à Saúde.Departamento de Promoção da Saúde.Guia alimentar para crianças brasileiras menores de 2 anos. Brasília, DF; 2019. 265 p. [citado 20 mai 2020]. Disponível em: http://189.28.128.100/dab/docs/portaldab/publicacoes/guia_da_crianca_2019.pdf

17. Brasil. Ministério da Saúde. Secretaria de Vigilância em Saúde. Departamento de Análise em Saúde e Vigilância de Doenças não Transmissíveis. Vigitel Brasil 2018: vigilância de fatores de risco e proteção para doenças crônicas por inquérito telefônico: estimativas sobre frequência e distribuição sociodemográfica de fatores de risco e proteção para doenças crônicas nas capitais dos 26 estados brasileiros e no Distrito Federal em 2018. Brasília: Ministério da Saúde, 2019. 132.: il

18. Food and Agriculture Organization of the United Nations. World Health Organization. Fruit and Vegetables for Health. Report of a Joint FAO/WHO Workshop, 1-3 September 2004, Kobe, Japan. [citado em 22 mai. 2020]. Disponível em: http://www.fao.org/3/a-y5861e.pdf

19. Viellas EF, Domingues RMSM, Dias MAB, Gama SGN, Theme Filha MM, Costa JV, et al. Assistência pré-natal no Brasil. Cad Saúde Pública. 2014; 30 (Sup): S85-S100.

20. Mario DN, Rigo L, Boclin KLS, Malvestio LMM, Anziliero D, Horta BL, et al. Qualidade do Pré-Natal no Brasil: Pesquisa Nacional de Saúde 2013.Ciên Saúde Coletiva. 2019; 24 (3): 1223-32

21. Gomes CB, Malta MB, Martiniano ACA, Di Bonifácio LP, Carvalhaes MABL. Práticas alimentares de gestantes e mulheres não grávidas: Há diferenças? Rev Bras Ginecol Obstet. 2015; 37 (7): 325-32

22. Jardí C, Aparicio E, Bedmar C, Aranda N, Abajo S, March G, et al. Food Consumption during Pregnancy and PostPartum. ECLIPSES Study. Nutrients. 2019; 11 (10): 2447.

23. GBD 2017 Diet Collaborators. Health effects of dietary risks in 195 countries, 1990
2017: a systematic analysis forthe Global Burden of Disease Study 2017. Lancet. 2019; 393: 1958-72.

24. Aune D, Giovannucci E, Boffetta P, Fadnes LT, Keum N, Norat T, et al. Fruit and vegetable intake and the risk of cardiovascular disease, total cancer and allcause mortalitya systematic review and doseresponse meta-analysis of prospective studies. Int J Epidemiol. 2017; 1-28.

25. Muraki I, Imamura F, Manson JE, Hu FB, Willett WC, van Dam RM, et al. Fruit consumption and risk of type 2 diabetes: results from three prospective longitudinal cohort studies. BMJ. 2013; 347:f5001.

26. Brasil. Ministério da Saúde. Universidade Federal de Minas Gerais. Desmistificandodúvidas sobre alimentação e nutrição: material de apoio para profissionais de saúde. Brasília, DF; 2016. 164 p.

27. Brasil. Ministério da Saúde. Secretaria de Atenção à Saúde. Departamento de Atenção Básica. Cadernos de Atenção Básica.Atenção ao pré-natal de baixo risco. Brasília, DF; 2012. 318 p. (Cadernos de Atenção Básica, n 32).

28. Louzada MLC, Martins APB, Canella DS, Baraldi LG, Levy RB, Claro RM, et al. Alimentos ultraprocessados e perfil nutricional da dieta no Brasil. Rev Saúde Pública. 2015; 49: 38

29. Silva CA, Santos IS, Shivappa N, Hebert JR, Crivellenti LC, Sartorelli DS. The role of food processing in the inflammatory potential of diet during pregnancy. Rev Saúde Pública. 2019; 53: 113.

30. Gomes CB, Vasconcelos LG, Cintra RMGC, Dias LCGD, Carvalhaes MABL. Hábitos alimentares das gestantes brasileiras: revisão integrativa da literatura. Ciên Saúde Coletiva. 2019; 24 (6): 2293-2306

Received on October 5, 2020

Final version presented on February 2, 2021

Approved on March 30, 2021 